On the "Inverse" Isotope Effect in Organic Superconductors: New Findings and Implications

Aravinda M. Kini, John A. Schlueter, Brian H. Ward, Urs W. Geiser, and H. Hau Wang

Chemistry and Materials Science Divisions

Argonne National Laboratory

Argonne, IL 60439

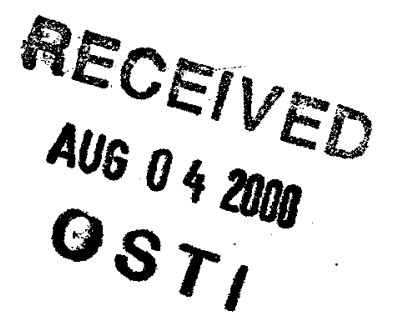

submitted for publication in the

Proceedings of the International Conference on the Science and Technology of

Synthetic Metals (ICSM 2000), Badgastein, Austria, July 15-21, 2000

The submitted manuscript has been created by
the University of Chicago as Operator of
Argonne National Laboratory ("Argonne") under
Contract No. W-31-109-ENG-38 with the U.S.
Department of Energy. The U.S. Government
retains for itself, and others acting on its behalf,
a paid-up, nonexclusive, irrevocable worldwide
license in said article to reproduce, prepare
derivative works, distribute copies to the public,
and perform publicly and display publicly, by
or on behalf of the Government.

*Work supported by the U.S. Department of Energy, BES-Materials Sciences, under Contract W-31-109-ENG-38. 
To be presented at the International Conference

on the Science and Technology of Synthetic Metals, ICSM 2000,

Badgastein, Austria, July 15-21, 2000.

\title{
On the "inverse" isotope effect in organic superconductors: new findings and implications
}

\author{
Aravinda M. Kini, ${ }^{*}$ John A. Schlueter, Brian H. Ward, Urs W. Geiser and H. Hau Wang \\ Chemistry and Materials Science Divisions, Argonne National Laboratory, 9700 South Cass Avenue, Argonne, IL 60439, USA \\ Received ; accepted
}

\begin{abstract}
The "inverse" deuterium isotope effect, previously found in $\mathrm{K}-(\mathrm{BEDT}-\mathrm{TTF})_{2} \mathrm{Cu}(\mathrm{NCS})_{2}$, is also found in two other BEDT-TTF based superconductors with different packing motifs and different types of anions. Remarkably, the magnitude of the isotope shift is essentially identical in all three superconductors, $c a .+0.26 \pm 0.06 \mathrm{~K}$. These results, when taken together with the recent results of Lang et al. on the uniaxial pressure derivatives of $T_{\mathrm{c}}$, suggest that the "inverse" isotope effect may not have a direct relationship to the pairing mechanism but instead is a reflection of the change in the "internal lattice pressure".
\end{abstract}

Keywords: Organic superconductors, BEDT-TTF or ET, isotope effect on $T_{\mathrm{c}}, \mathrm{BCS}$ theory

\section{Introduction}

Despite intense research efforts towards understanding the nature of electron-pairing mechanism in organic superconductors, a consensus has not yet emerged. Experimental evidence has been presented in support of both conventional (phonon-mediated, BCS, $s$-wave order parameter symmetry) and unconventional (not phononmediated, non-BCS, $d$-wave order parameter symmetry) mechanisms [1]. Our comprehensive and carefully performed isotope effect studies have revealed two competing isotope effects in the ambient pressure organic superconductor $\mathrm{K}$-(BEDT-TTF $)_{2} \mathrm{Cu}(\mathrm{NCS})_{2}-\mathrm{a}$ "normal" isotope shift (lowering of $T_{\mathrm{c}}$ ) when the largest possible mass increase of BEDT-TTF (hereafter ET) molecule is achieved by ${ }^{34} \mathrm{~S}$ and ${ }^{13} \mathrm{C}$ labelling and an "inverse" isotope shift (increase in $T_{\mathrm{c}}$ ) when hydrogen $(\mathrm{H})$ atoms in ET molecule are replaced by deuterium (D) [2]. While the former effect is a clear indication for the involvement of lattice phonon modes in electron-pairing, the latter effect can not be reconciled with any existing theoretical models. In this connection, we have continued our isotope effect studies to determine whether the "inverse" $D$ isotope effect

\footnotetext{
*orresponding author: Tel: (630) 252-3468; Fax: (630) 252-4470; Email: amkini@anl.gov

\# Work at Argonne National Laboratory is sponsored by the U.S. Department of Energy, Office of Basic Energy Sciences, Division of Materials Sciences, under Contract W-31-109-ENG-38.
}

is specific to $\mathrm{K}$-(BEDT-TTF $)_{2} \mathrm{Cu}(\mathrm{NCS})_{2}$ or is more universal in nature. We have now found that it occurs in at least two other ET based superconductors, viz., $\mathrm{K}_{\mathrm{L}^{-}}$ (ET) ${ }_{2} \mathrm{Ag}\left(\mathrm{CF}_{3}\right)_{4}(\mathrm{BDCE})$ where BDCE is 1-bromo-1,2dichloroethane [3] and $\beta^{\prime \prime}-(\mathrm{ET})_{2} \mathrm{SF}_{5} \mathrm{CH}_{2} \mathrm{CF}_{2} \mathrm{SO}_{3}$. Furthermore, the magnitude of the isotope shift is essentially the same $(+0.26 \pm 0.06 \mathrm{~K})$ in all three superconductors (with $T_{\mathrm{c}}$ 's ranging from 2.9 to $9.2 \mathrm{~K}$ ), irrespective of the donor packing motifs ( $\mathrm{K}$ or $\beta^{\prime \prime}$ ) or the nature of the counter anions (polymeric or discrete or organometallic). In the meantime, Müller, Lang and coworkers have determined uniaxial pressure coefficients of $T_{\mathrm{c}}$ in $\mathrm{K}$-(ET) $)_{2} \mathrm{Cu}(\mathrm{NCS})_{2}$ and $\beta "$-(ET) $)_{2} \mathrm{SF}_{5} \mathrm{CH}_{2} \mathrm{CF}_{2} \mathrm{SO}_{3}$ by high-resolution measurements of the coefficients of thermal expansion, and have found a large negative uniaxial stress effect perpendicular to the conducting planes in both superconductors [4]. These two results, when taken together, strongly suggest that the "inverse" D isotope shift may not be directly related to the electron-pairing mechanism, but rather to the change in "internal lattice pressure".

\section{Results and Discussion}

As a continuation of our isotope effect studies [2,3], we have recently determined the effect of $D$ substitution in the ET portion of $\beta^{\prime \prime}-(\mathrm{ET})_{2} \mathrm{SF}_{5} \mathrm{CH}_{2} \mathrm{CF}_{2} \mathrm{SO}_{3}$. The same preparative, measurement and data analysis protocols as used previously by us were employed, and they are described in detail elsewhere [5]. An "inverse" isotope shift of $+0.27 \pm 0.06 \mathrm{~K}$ was found for this completely 
Table 1

Summary of H-to-D isotope shifts and uniaxial pressure derivatives (perpendicular to conducting planes) in three superconductors

\begin{tabular}{lccc}
\hline \multicolumn{1}{c}{ Superconductor } & $T_{\mathrm{c}}(\mathrm{K})$ & $\Delta T_{\mathrm{c}}(\mathrm{K})$ & $\left(\partial T_{\mathrm{d}} / \partial p\right)_{\perp}(\mathrm{K} / \mathrm{kbar})$ \\
\hline $\mathrm{K}_{\mathrm{L}}-(\mathrm{ET})_{2} \mathrm{Ag}\left(\mathrm{CF}_{3}\right)_{4}(\mathrm{BDCE})$ & $2.90 \pm 0.04$ & $0.21 \pm 0.06$ & - \\
$\beta^{\prime \prime}-(\mathrm{ET})_{2} \mathrm{SF}_{5} \mathrm{CH}_{2} \mathrm{CF}_{2} \mathrm{SO}_{3}$ & $4.34 \pm 0.05$ & $0.27 \pm 0.06$ & $-5.9 \pm 0.25$ \\
$\mathrm{~K}-(\mathrm{ET})_{2} \mathrm{Cu}(\mathrm{NCS})_{2}$ & $9.20 \pm 0.05$ & $0.30 \pm 0.07$ & $-6.2 \pm 0.25$ \\
\hline
\end{tabular}

organic superconductor. In Figure 1, we graphically illustrate the "inverse" isotope effect found so far in three different superconductors, which are of essentially the same magnitude within experimental uncertainties (see also Table 1).

In Table 1, we have also included the uniaxial pressure coefficients of $T_{c}$ for $\kappa-(\mathrm{ET})_{2} \mathrm{Cu}(\mathrm{NCS})_{2}$ and $\beta$ "$(\mathrm{ET})_{2} \mathrm{SF}_{5} \mathrm{CH}_{2} \mathrm{CF}_{2} \mathrm{SO}_{3}$ perpendicular to the conducting planes. These were obtained from high resolution measurements of the coefficient of thermal expansion, $\alpha=$ $\Gamma^{1} \times(\partial l / \partial T)$, on single crystals of the two superconductors, which show large and highly anisotropic phase transition anomalies at $T_{\mathrm{c}}$ [4]. By combining the thermal expansion data with the literature results on the specific heat and by use of the Ehrenfest equation, the uniaxial pressure coefficients were obtained. The most notable finding is that the uniaxial pressure derivatives perpendicular to the conducting plane, i.e., along $a^{*}$ in $\mathrm{K}-(\mathrm{ET})_{2} \mathrm{Cu}(\mathrm{NCS})_{2}$ and $c$ in $\beta^{\prime \prime}-(\mathrm{ET})_{2} \mathrm{SF}_{5} \mathrm{CH}_{2} \mathrm{CF}_{2} \mathrm{SO}_{3}$, are rather large and of nearly the same magnitude, $-5.9 \pm 0.25$ and $-6.2 \pm 0.25 \mathrm{~K} / \mathrm{kbar}$ respectively. The essentially similar and large negative values of the uniaxial pressure derivative in two different superconductors now provide new insights into why the $D$ isotope effect is "inverse" and is of the same magnitude.

In this connection, it is necessary to know what if any changes in the lattice parameters are caused by the H-to-D substitution in these materials, because it has been argued that the inverse isotope shift could be an outcome of changes in the lattice parameters and consequently the band structure. Watanabe et al. have showed by four-circle single crystal $\mathrm{X}$-ray diffraction $(300-12 \mathrm{~K})$ studies that the $\mathrm{H}$-to-D isotopic substitution in both $\mathrm{K}-(\mathrm{ET})_{2} \mathrm{Cu}(\mathrm{NCS})_{2}$ and $\kappa-(\mathrm{ET})_{2} \mathrm{Cu}\left[\mathrm{N}(\mathrm{CN})_{2}\right] \mathrm{Br}$ results in no significant changes in the lattice parameter perpendicular to the conducting planes, although measurable changes occur in other lattice parameters at low temperatures [6]. Since $\mathrm{C}-\mathrm{H}(\mathrm{D})$ bonds in ET-based superconductors are oriented perpendicular to the planes, and $\mathrm{C}-\mathrm{D}$ bonds have a smaller zero point displacement compared to $\mathrm{C}-\mathrm{H}$ bonds, $\mathrm{H}$-to-D substitution should result in longer (or softer) intermolecular contacts with the atoms in the anion and with other donor molecules [7]. In other words, the "internal lattice pressure" perpendicular to the planes becomes smaller as a result of the H-to-D substitution, and this change is expected to be of the same magnitude irrespective of the anion or the packing motif within the conducting plane. Since the large negative pressure derivative of $T_{\mathrm{c}}$ in the direction perpendicular to the planes is the same for the two superconductors, it therefore follows that the observed isotope shift is merely an outcome of the lowering of the "internal lattice pressure".

Finally, we note that the "inverse" D isotope effect is a clear indication of the importance of interlayer coupling in layered organic superconductors, and may not be directly linked to what mediates electron-pairing. Whangbo et al. have suggested that within the framework of the generalized BCS model and the McMillan equation, the $\mathrm{H}$ to-D substitution should result in a "softer" lattice and a larger $\lambda$ (electron-phonon coupling constant), and hence a higher $T_{\mathrm{c}}[7,8]$.

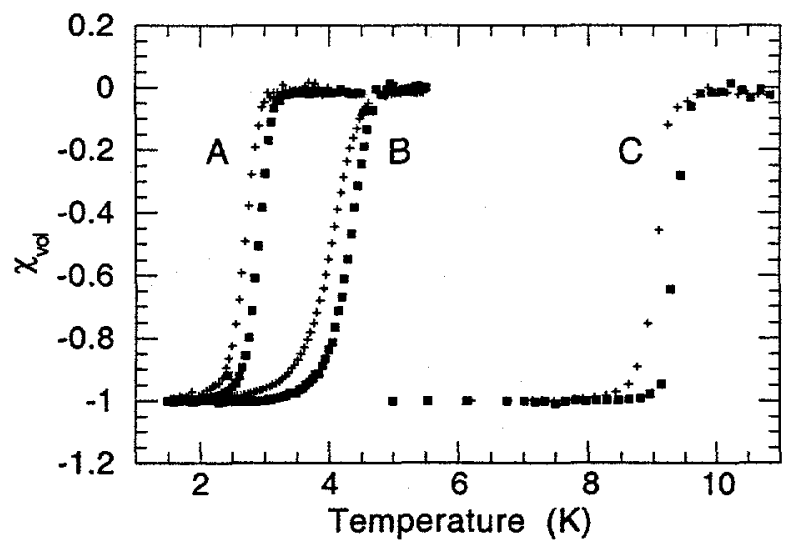

Fig. 1. Representative superconducting transition curves (by a.c. susceptibility) of (A) $\kappa_{\mathrm{L}}-(\mathrm{ET})_{2} \mathrm{Ag}\left(\mathrm{CF}_{3}\right)_{4}(\mathrm{BDCE}),(\mathrm{B})$ $\mathrm{B}^{\sim}$-(ET) $)_{2} \mathrm{SF}_{5} \mathrm{CH}_{2} \mathrm{CF}_{2} \mathrm{SO}_{3}$ and (C) $\kappa-(\mathrm{ET})_{2} \mathrm{Cu}(\mathrm{NCS})_{2}$. Plus symbols $=\mathrm{H}$; filled squares $=\mathrm{D}$.

\section{References}

[1] See e.g., J. Wosnitza, J. Low Temp. Phy. 117 (1999) 1701; M. Lang, Supercond. Rev. 2 (1996) 1.

[2] A. M. Kini et al. Synth. Met. 85 (1997) 1617 and references therein.

[3] J. A. Schlueter et al. Physica C, 265 (1996) 163.

[4] J. Müller et al. Phys. Rev. B, 61 (2000) 11739.

[5] J. A. Schlueter et al. Physica $C$, Submitted.

[6] Y. Watanabe et al. Synth. Met, 86 (1997) 1917.

[7] J. M. Williams et al. Science, 252 (1991) 1509.

[8] M.-H. Whangbo et al. in V. Z. Kresin and W. L. Little, (eds.), Organic Superconductivity, Plenum, New York, 1991, p. 243. 


\section{DISCLAIMER}

This report was prepared as an account of work sponsored by an agency of the United States Government. Neither the United States Government nor any agency thereof, nor any of their employees, make any warranty, express or implied, or assumes any legal liability or responsibility for the accuracy, completeness, or usefulness of any information, apparatus, product, or process disclosed, or represents that its use would not infringe privately owned rights. Reference herein to any specific commercial product, process, or service by trade name, trademark, manufacturer, or otherwise does not necessarily constitute or imply its endorsement, recommendation, or favoring by the United States Government or any agency thereof. The views and opinions of authors expressed herein do not necessarily state or reflect those of the United States Government or any agency thereof. 


\section{DISCLAIMER}

Portions of this document may be illegible in electronic image products. Images are produced from the best available original document. 